\title{
Probable common origin of a hereditary fundus dystrophy (Sorsby's familial pseudoinflammatory macular dystrophy) in an English and Australian family
}

\author{
H. KALMUS and D. SEEDBURGH \\ From the Galton Laboratory, Department of Human Genetics and Biometry, University College, London
}

Summary. A genealogical link was established six generations back between a family living in England and Australia, and one of the families reported originally by Sorsby et al (1949) as suffering from autosomal dominant inflammatory macular dystrophy (fundus dystrophy).

The onset-in the fifth decade of life-and the progress of the condition, which usually ends in blindness, has been observed in a number of patients and the prodromal development of a colour vision deficiency in some of them confirmed. This defect is fundamentally different from the X-linked colour vision defects and merits further investigation.

Allelism of genes, responsible for similar though often differently named pathological syndromes in separate human families, cannot be tested by crossing. This makes conclusions concerning genetical identity, chromosomal localization, and linkage uncertain, and prognosis and genetical counselling may also be impaired. Furthermore, the full manifestation of a syndrome including prodromal symptoms may escape some observers. It is, therefore, of some interest when common ancestry can be established between families formerly thought to be unconnected, who have similarly affected members.

An opportunity to establish such a relationship arose from a letter from Dr D. C. Wallace of Brisbane on the 29 December 1969, describing a family containing people suffering from a pseudoinflammatory macular dystrophy (Fraser and Wallace, 1971) which he suspected to be identical with a fundus dystrophy described by Sorsby (1940) and Sorsby, Mason, and Gardner (1949). Dr Wallace wondered whether a 'deutan defect' occurring in the family was an early manifestation of the same gene which later brought about the macular dystrophy as suggested by Björk, Lindblow, and Wadenstein (1956) for some kinds of macular degeneration, or whether its occurrence in the pedi-

Received 3 June 1975. gree was purely coincidental. $\mathrm{He}$ also indicated that the family was spread widely in Britain, Australia, and New Zealand.

On receiving a further letter containing names and addresses of English relations of the Australian family contact was made, and several affected members of the family were found. Colour vision deficiency was also observed in some of them. Genealogical search then brought to light a highly probable connexion with Number 1 of Sorsby et al's five pedigrees, namely the Randall family. According to descriptions by Sorsby and Fraser and Wallace and our own observations the macular dystrophy in our family is an autosomal dominant trait, with onset during middle age. Prodromal colour vision deficiency may precede the often sudden development of a central scotoma in one eye followed by the development of a similar lesion in the other eye. Fundoscopy shows at this time an inflamed macula with exudative retinoschisis and peripheral haemorrhage. Later on the process spreads, with chorioidal sclerosis, atrophy, and some deposition of pigment. Some peripheral vision is usually retained for many years.

Genealogical and pedigree findings

The probable connexion between Fraser and 


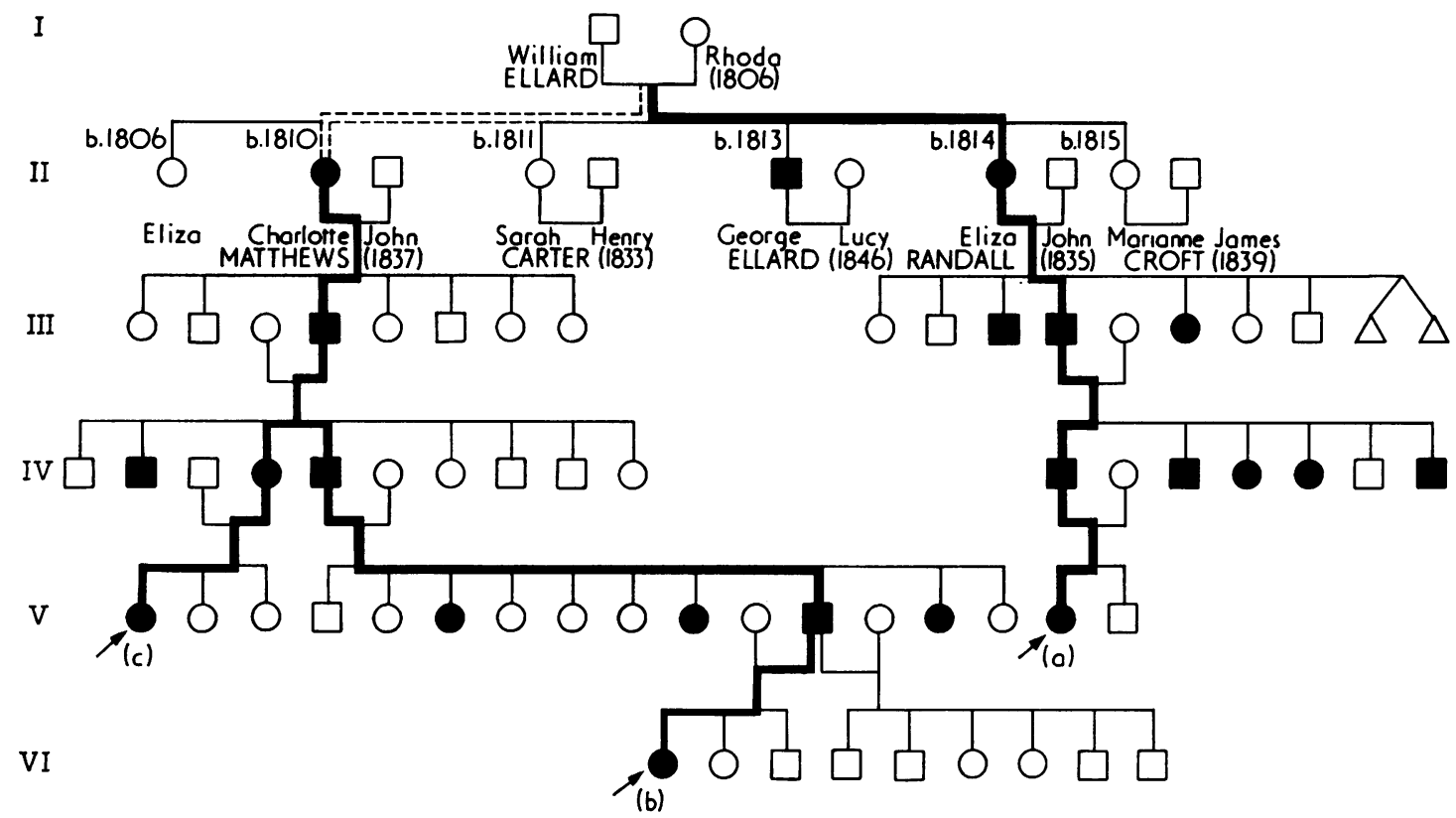

FIG. 1. Pedigree joining families presented by Sorsby et al (propositus a), Fraser and Wallace (propositus b), and our main informant (c). Only direct line of descent and sibships are shown. Dates of marriages in brackets.

Wallace's sibship via their English relations and the Randall family described by Sorsby et al emerged in the following way.

The pedigree shown in Fig. 2 was constructed from information given by Mrs B (IV.2) who is also (c) in Fig. 1; her name and address we had received from Dr Wallace. On obtaining the birth certificate of Mrs B.'s grandfather Isaac M. (II.6) it was discovered that this man's mother, Charlotte (I.2), had the maiden name of Ellard; and on scrutinizing Sorsby's pedigrees we found that this was also the maiden name of Mrs John Randall, the progenetrix of his first family (see Fig. 1).

Our next endeavour was to establish the relationship between these two ladies, born Ellard.

Records in St Ippollitt's Church, Hertfordshire, gave details of the marriages in 1835 of Elizabeth Ellard to John $\mathrm{F}$ andall and of Charlotte Ellard to John Matthews in 1837. A witness at the EllardRandall wedding was Charlotte Ellard and a witness at the Ellard-Matthews wedding was Mary Ann Ellard. Mary Ann Ellard was herself married in the same church in 1839 and her witness was George Ellard, who according to baptismal records was the child of William and Rhoda (née Field) as were also Elizabeth and Mary Ann. George Ellard is probably the blind brother of Mrs Randall reported by Sorsby et al. All this made us suspect that Elizabeth and Charlotte Ellard were sisters; but this was difficult to show conclusively. From the baptismal records now kept in the Archives Department of Hertfordshire County Council it was established that William and Rhoda Ellard were married in January 1806 at Kings Walden and had a daughter Eliza baptized there in September 1806. No further record of children could be found until 1811 when a daughter Sarah was baptized in Hitchin. She was followed by a son George in 1813 and a second daughter Eliza in 1814 and lastly by a daughter Marianne in 1815.

As William and Rhoda Ellard named a second daughter Eliza one may assume that the first Eliza died in infancy. There are also 2 discrepancies in naming. Eliza of the baptismal records becomes Elizabeth in her marriage certificate and similarly Marianne becomes Mary Ann.

The fact we could not definitely establish was whether Charlotte Ellard (I.2) was in fact a sister of Elizabeth (Eliza). There is no record of birth or baptism of any Charlotte Ellard in the Hitchin area from 1806 to 1820. A search by Hertfordshire Council Archivists was also unsuccessful. However, according to the 1851 Census a Charlotte Matthews (née Ellard) of Stevenage gave her birth date as 1810 and place of birth as Hitchin. (Among her children recorded in the census is one Isaac 

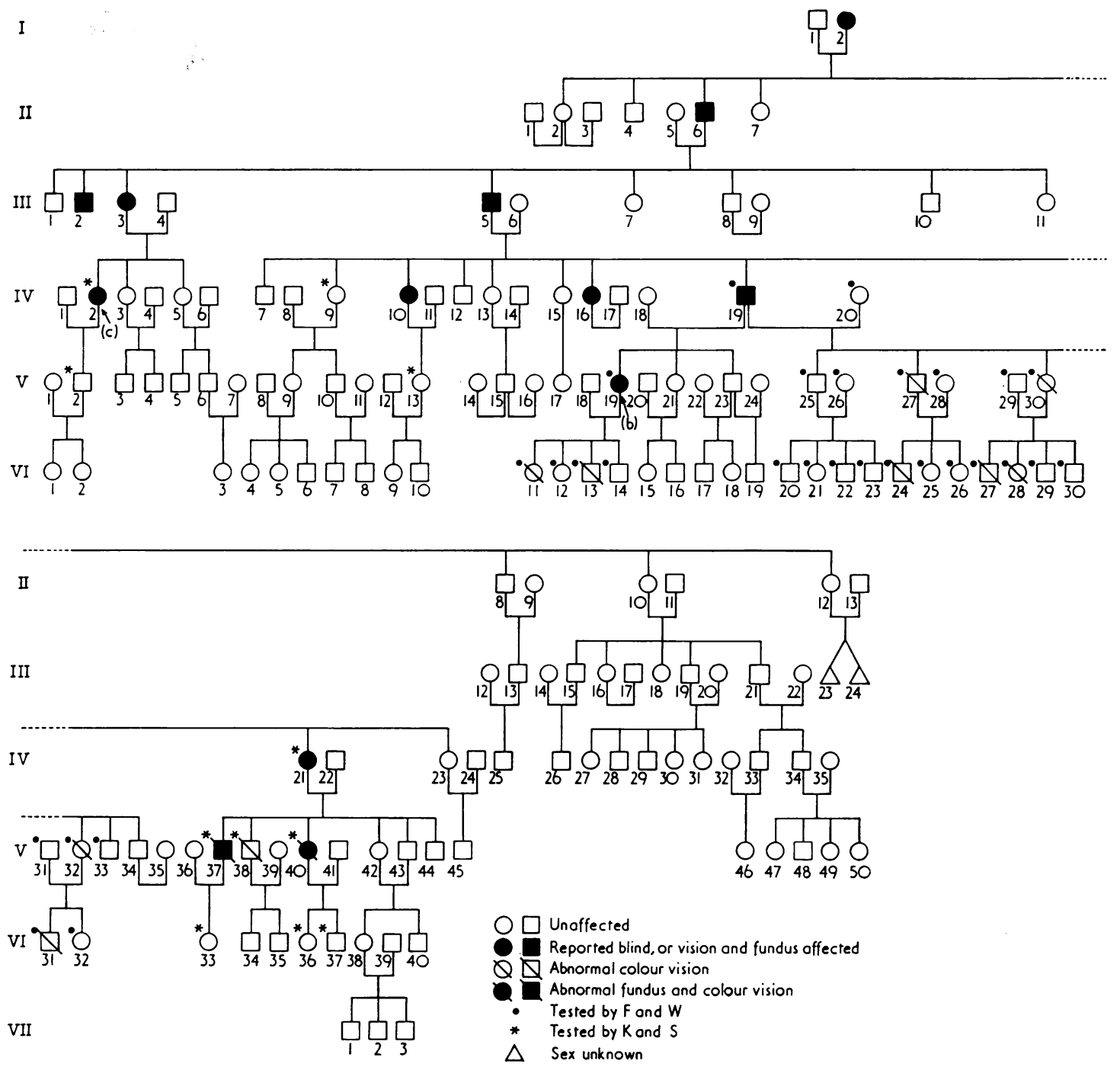

Fig. 2. Pedigree of family described by Fraser and Wallace plus our additional data. Arrowsi ndicate individuals (b) and (c) from Fig. 1. Most of the unaffected individuals in generations V, VI, and VII are under the age of onset.

(Fig. 2, II.6) born 1841 confirmed by us by means of his birth certificate.) Why then does she not occur in the Hitchin birth register? Charlotte might perhaps have been born not in Hitchin but farther afield than the area of Hertfordshire searched by us; alternatively and more probably she may have failed to be recorded in the baptismal register. Such an omission is conceivable considering that it has been estimated (Krause (1965) quoted by Roberts and Rawlings, 1974) that approximately $10 \%$ of births were not recorded in the baptismal records of England before 1837; while mar- riages have been more accurately and comprehensively dealt with (Cox, 1910).

In conclusion it still seems highly probable that Elizabeth Ellard the progenetrix of the Randall pedigree and Charlotte Ellard the progenetrix of the Matthews pedigree were sisters. Even if they were not sisters they must have been close relatives, perhaps cousins, considering all the circumstances, and the occurrence of a rare hereditary disease in the offspring of the two women must be ascribed to a single mutation in a common ancestor.

The pedigree of the offspring of John Randall and 
Elizabeth (née Ellard) was published by Sorsby et al (1949) and part of the pedigree originating from John Matthews and Charlotte (née Ellard) by Fraser and Wallace (1971).

Further pedigree details concerning the Matthews family were provided by IV.2 and corroborated by IV.9, IV.10, and IV.21 (Fig. 2). Statements by these people and V.13 also indicated a general similarity of manifestation and onset of the condition in the Australian and English members of the family.

Another informant IV.34 wrote to us saying that neither he nor any of the offspring of II.10 whose pedigree he provided had ever shown any manifestation of the dystrophy.

\section{Investigation of individuals}

The purpose of this paper was not to produce a detailed clinical description of all members of the family but merely (1) to establish the identity of the gene responsible for the dystrophy in the Sorsby et al and Fraser and Wallace pedigrees, and (2) to investigate the prodromal colour vision deficiency. Thus only a few indibiduals were investigated by us. The results are given below and one report by an ophthalmologist is given more fully.

Mrs B. IV.2 (age 72). Reported onset of disease at age 45 years when noticed difficulties doing close work. In spite of reassurance by optician sight deteriorated within 6 weeks to extent that she was unable to read; after that, slow further deterioration. Has not seen an optician for 27 years and is now registered as blind. Reported that her colour vision had always been poor. When tested knew the difference between daylight and artificial light. Described red light projected onto a wall as a reddish glow; white as white; blue as grey or blue; magenta as pinkish; deep green as dark blue and light green as dark, but of indefinite colour. Fundus photographs (Fig. 3a and b).

Mr B. V.2 (age 46). Has worn glasses for television and cinema for about 8 years, otherwise vision normal. Reported difficulty in distinguishing shades of orange, pink, and brown, and of mauve and maroon, but does not make any mistakes with Ishihara at $6500^{\circ} \mathrm{K}$ nor with HRR charts. Reading on the colour rule (Kalmus, 1972) normal. Discs, blood vessels, chorioids, and maculae normal.

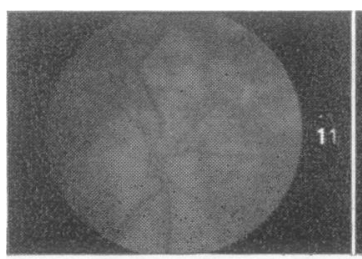

FIG. 3. Mrs B. IV.2 (a) Right disc; (b) right macula. Both fundi show pigmentary aggregation especially involving the macular region, with tenuous arteries and pallor of the discs.

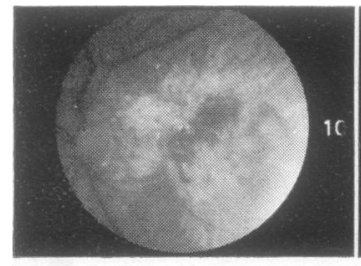

(a)

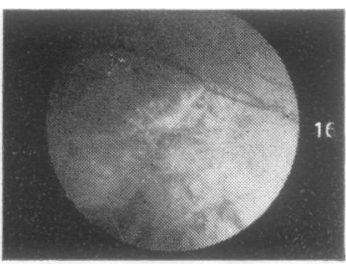

(b)

FIG. 4. Mrs W. IV.21 (a) Left disc and macula; (b) right macula. Widespread retinal degeneration with aggregation of pigment at both maculae. Tenuous arteries and pallor of left disc.

Mrs W. IV.21 (age 69). Vision severely impaired, but watches television from nearby; shops unaccompanied. First glasses at 30 years of age, still able to read at the age of 56. Later noticed a black mark size of clockface, especially in dim light suggesting scotomata in both eyes. When seen by us could only read first (demonstration) Ishihara chart when using both eyes. Remembered having difficulties with mauve and brown shades when asked about past colour vision. Fundus (Fig. 4a and 1b).

Mr J.W. V.37 (age 48). Was crack shot during World War II but noticed sight deterioration at age 46 years. Two years later at time of examination was still driving car. Central scotomata at low illumination not noticeable in daylight. Central colour vision impairedred appears desaturated. Fourteen incorrect Ishihara readings with right eye, however left eye could not decipher even demonstration plate. On tritan chart (Kalmus, 1955) saw green square only excluding tritanopia. On Pickford's anomaloscope had wide tolerance around normal match. Colour naming uncertain. Left fundus see Fig. 5a and b. Right fundus normal.

Mrs S. V.13 (age 33). Tested in laboratory, found to have normal vision and colour vision.

Mrs R. IV.10 (age 74). Unwilling to be examined because of ill health. According to daughter (Mrs S. V.13) recognizes face nearby or $£ 1$ note, but cannot read and recognizes coins only by touch. Refuses to be registered as blind. Noticed difficulties with colour at 49 years of age; later sight deteriorated and Moorfields Hospital diagnosed macular haemorrhage.

Mrs Wh. IV.16 (age 68). Report from letter dictated by patient to husband. Eye trouble became apparent 23 years ago and was diagnosed at Moorfields

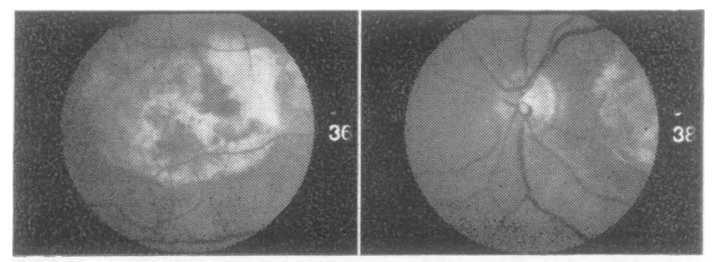

(a)

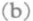

FIG. 5. Mr J.W. V.37 (a) Left macula; (b) left disc. Circumscribed area of degeneration at left macula with areas of pigmentary clumping. Left disc and vessels appear normal. 
Hospital as macular haemorrhage. Gradual deterioration ensued and is now registered as blind. However, some vision still retained varying somewhat with state of health, and weather.

Mrs D. IV.9 (age 78). On testing found to have normal vision for age and also normal colour vision.

Mr E.W. V.38 (age 50). Occupation taxidriver. Slightly hypermetropic; visual acuity normal when wearing glasses. No ophthalmological history. $\mathrm{Re}$ ported no difficulty with traffic lights, not aware of any colour defect. Wife said he was colour blind though did not know for how long affected. Ishihara test (under $6500^{\circ} \mathrm{K}$ ) wearing glasses using both eyes could only read first three plates correctly; unable to read any others including those usually seen by defectives. On Pickford Nicholson anomaloscope accepted a normal match. Extreme red settings described as 'darker' dubiously as reddish. Extreme green settings were called 'more yellow'. On Lovibond colour analyser (Dain, 1971) accepted many settings besides normal even at high saturation of 43 . This appears to be prodromal disturbance of colour vision of which his sister's defect is more advanced.

Mrs P. V.40 (age 49). According to report given by Mr P. J. L. Hunter (Norfolk and Norwich Hospital) when first seen complained of distorted vision in left eye. Visual acuity in right eye $6 / 9$ and in left $6 / 12$ with correction. Four months later visual acuity in left eye dropped to $6 / 60$. Fundus picture showed chorioidal sclerosis 'Drusen-like' changes with macular haemorrhage and some vitreous changes superficially to this; all had deteriorated by second visit. Unable to read any of Ishihara plates, not even first demonstration chart. Five months later when seen by ourselves described onset of symptoms as follows: about 3 years ago first started arguing with husband about colours particularly black/ brown and blue/green. Two years later suddenly felt a pain above left eye and noticed that vertical contour of door looked curved. Three months later saw $\mathrm{Mr}$ Hunter for first time.

Left eye was retested with Ishihara plates by us, she could not see orange 12 on demonstration chart, but then fleetingly saw number only to lose it again quickly. None of other charts, including those decipherable by colour defectives, were read. However she was able to name colours of both background and parts of numbers on remaining charts, usually accurately except for charts 10-13 (orange, numbers on green background), where she did not see any orange. With right eye could read demonstration chart and 6 on chart 3 , but no others, but again identified all colours including those on charts 1013-this time with greater ease and accuracy. Reading tritan chart (Kalmus, 1955) with right eye could see only green square, a finding excluding tritanopia but indicative of abnormal red-green vision. With left eye green square was only seen momentarily. On similar chart only part of green numeral was seen at particular moment.

Readings on HRR charts impossible with left eye but readings with right eye indicative of some green deficiency. Matches on $\mathrm{D}$ and $\mathrm{H}$ colour rule (Kalmus, 1972; Kalmus et al, 1974a, b) quite different from those

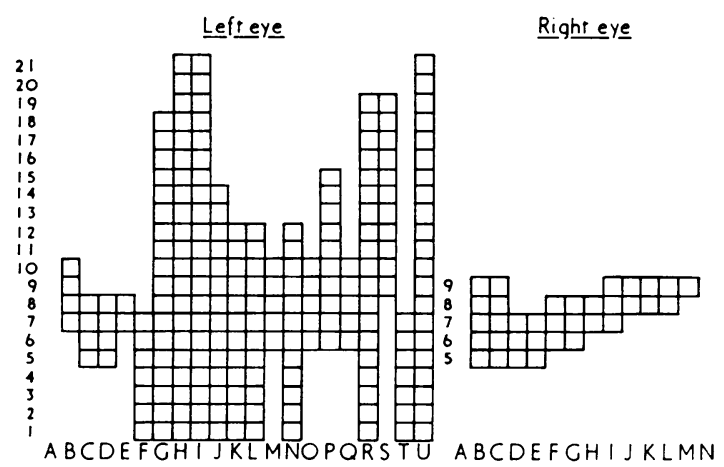

FIG. 6. Matching areas of D and $H$ colour rule; of Mrs $P(I V .40)$ in natural daylight.

obtained from people with hereditary stationary colour vision defects or with glaucoma when using left eye (Fig. 6). Matching area of less affected right eye was similar to tritan patterns.

Miss J.P. VI.36 and Mr M.P. VI.37 (ages 20 and 17). Neither showed any impairment in visual acuity when corrected for slight refraction anomalies nor colour vision deficiencies when tested on Ishihara charts, HRR, tritan charts, or colour rule.

Miss W. VI.33 (age 26). Showed no impairment in visual acuity when corrected for myopia nor any colour vision deficiency when tested on Ishihara charts, or with HRR, trittan charts, Pickford's anomaloscope, colour rule, or Lovibond colour analyser.

\section{Discussion}

The occurrence in large numbers and in families disposed over wide areas of Sorsby's fundus dystrophy indicates that it does not greatly diminish fitness and that the fixation of the responsible mutant gene is probably a matter of chance rather than a consequence of selection. This agrees with the determination of all interviewed patients to minimize the importance of their affliction, irrespective of their expectations. These ranged from a clear understanding of the prospects of becoming blind themselves and the probability of transmitting the condition to their offspring to a muddled denial of prodromal symptoms.

The onset of serious symptoms is usually in the fifth decade of life and varies in detail, but it is difficult to determine precisely the first visual and ocular changes in each case and whether in fact there is a regular sequence of visual losses. The rapidity and extent of deterioration also varies a good deal as does the interval between the processes in the two eyes. Some early deterioration of colour sense is often reported. However, the resulting defects are quite different from those caused by the sex-linked genes; therefore attempts to classify the defects as 
deutan, etc. are not justified. Probably the colour sense is disturbed in a mosaic fashion on the retina and not in a regular manner as in stationary colour vision defects. As the phase of the disease in which only colour vision is seriously affected is of uncertain duration it is difficult to test this hypothesis in many people. Fraser and Wallace suspected colour deficiency in a few children in the family and described deficiencies in some otherwise unaffected adults between 20 and 40 years of age. In our limited material we did not find any such early cases. Thus, colour vision testing in young persons at risk for macular dystrophy is of limited value.

Fundus photography was done at the Insitute of Ophthalmology, Judd Street, London, and evaluated by Mr I. Luke, Moorfields Eye Hospital, High Holborn, London. Dr G. Stewart, Northwick Park Hospital, Middlesex, provided some fundus descriptions.

\section{REFERENCES}

Bjôrk, A., Lindblow, U., and Wadenstein, L. (1956). Retinal degeneration in hereditary ataxia. Fournal of Neurology, Neurosurgery and Psychiatry, 19,186-193.
Cox, J. C. (1910). The Parish Registers of England. Methuen, London.

Dain, S. J. (1971). A new colour vision test. Unpublished Ph.D. Thesis. City University, London.

Fraser, H. B. and Wallace, D. C. (1971). Sorsby's familial pseudoinflammatory macular dystrophy. American fournal of Ophthalmology, 71, 1216-1220.

Kalmus, H. (1955). The familial distribution of congenital tritanopia with some remarks on some similar conditions. Annals of Human Genetics, 20, 39-56.

Kalmus, H. (1972). Metameric 'colour rule' matches of normal, colour deficient, cataractic and aphakic observers. Annals of Human Genetics, 36, 109-118.

Kalmus, H., Luke, I., and Seedburgh, D. (1974a). Impairment of colour vision in patients with ocular hypertension and glaucoma. British fournal of Ophthalmology, 58, 922-926.

Kalmus, H., Neuhann, T., and Seedburgh, D. (1974b). Diagnosis of tritanopic vision by means of the D. \& H. color rule. Albrecht von Graefes Archiv für klinische und experimentelle Ophthalmologie, 191, 121-125.

Krause, J. T. (1965). The changing adequacy of English registration 1690-1837. In Population in History. Ed. by D. V. Glass and D. E. C. Eversley. Arnold, London.

Roberts, D. F. and Rawling, C. P. (1974). Secular trends in genetic structure: an isonymic analysis of Northumberland parish records. Annals of Human Biology, 1 (4), 393-410.

Sorsby, A. (1940). The dystrophies of the macula. British fournal of Ophthalmology, 24, 484-533.

Sorsby, A., Mason, M. E. J., and Gardner, N. (1949). A fundus dystrophy with unusual features. British fournal of Ophthalmo $\log y, 33,67-97$. 